\title{
Deep insights into interface engineering by buffer layer for efficient perovskite solar cells: a first- principles study
}

\author{
Le Huang ${ }^{1}$, Huafeng Dong ${ }^{2}$, Nengjie Huo ${ }^{3}$, Zhaoqiang Zheng ${ }^{1}$, Hui-Xiong Deng ${ }^{4}$, Gang Zhang ${ }^{5}$, \\ Yuan Cheng ${ }^{5^{*}}$ and Jingbo $\mathrm{Li}^{1,3^{*}}$
}

\begin{abstract}
Recent years have seen swift increase in the power conversion efficiency of perovskite solar cells (PSCs). Interface engineering is a promising route for further improving the performance of PSCs. Here we perform firstprinciples calculations to explore the effect of four candidate buffer materials (MACl, $\mathrm{MAI}, \mathrm{PbCl}_{2}$ and $\mathrm{PbI}_{2}$ ) on the electronic structures of the interface between $\mathrm{MAPbI}_{3}$ absorber and $\mathrm{TiO}_{2}$. We find that $\mathrm{MAX}(\mathrm{X}=\mathrm{Cl}, \mathrm{I})$ as buffer layers will introduce a high electron barrier and enhance the electronhole recombination. Additionally, MAX does not passivate the surface states well. The conduction band minimum of $\mathrm{PbI}_{2}$ is much lower than that of $\mathrm{MAPbI}_{3}$ absorber, which significantly limits the band bending of the absorber and open-circuit voltage of solar cells. On the other side, suitable bandedge energy level positions, small lattice mismatch with $\mathrm{TiO}_{2}$ surfaces, and excellent surface passivation make $\mathrm{PbCl}_{2}$ a promising buffer material for absorber/electron-transport-layer interface engineering in PSCs. Our results in this work thus provide deep understanding on the effects of interface engineering with a buffer layer, which shall be useful for improving the performance of PSCs and related optoelectronics.
\end{abstract}

Keywords: perovskite solar cells, buffer layer, interface engineering, band alignment, interfacial defect passivation

\section{INTRODUCTION}

As the leading composition and interface engineering technology, perovskite solar cells (PSCs) have advanced to reach power conversion efficiencies (PCE) over $23 \%$ in 10 years [1-14]. To further increase the efficiency of PSCs, contact passivation could be an effective way to improve the open-circuit voltage $\left(V_{\mathrm{OC}}\right)$. It is known that $V_{\mathrm{OC}}$ of solar cells is strongly related to the band bending of the absorber in the near-interface region, which is strongly limited by the deep interfacial states [15-20]. So treatment of the interface between the absorber and carrier transport layer is of great importance to improve the performance of PSCs.

Very luckily, it has been demonstrated that lead halide perovskite (LHP) absorbers, such as $\mathrm{MAPbI}_{3}$ and $\mathrm{FAPbI}_{3}$, have very good defect tolerance due to their substantially ionic bonding characteristic [21]. Dangling bonds at the surface of LHP nanocrystals have similar defect property with benign surface defects [22,23]. So another major obstacle to further improvement of PCE comes from the interfacial states at the interface of LHP absorber and carrier transport layer.

In PSCs, the most common electron transport layer (ETL) materials are $\mathrm{TiO}_{2}[8,24-26]$ and $\mathrm{SnO}_{2}$ in rutile structures $[14,27,28]$. It has been found that some deep interfacial states could be introduced at $\mathrm{LHP} / \mathrm{TiO}_{2}$ contact. As a result, the Fermi level can be completely or partially pinned by these deep states, limiting the band bending and $V_{\text {OC }}$ of PSCs [29,30]. Many efforts have been done to reduce the density of deep interfacial states by surface passivation [4,9,14,31-43]. Tan el al. [9] reported

\footnotetext{
${ }^{1}$ School of Materials and Energy, Guangdong University of Technology, Guangzhou 510006, China

${ }^{2}$ College of Physics and Optoelectronic Engineering, Shenzhen University, Shenzhen 518060, China

${ }^{3}$ Institute of semiconductor science and technology, South China Normal University, Guangzhou510631, China

${ }^{4}$ State Key Laboratory of Superlattices and Microstructures, Institute of Semiconductors, Chinese Academy of Sciences \& College of Materials Science and Opto-Electronic Technology, University of Chinese Academy of Sciences, Beijing 100083, China

${ }^{5}$ Institute of High Performance Computing, $A^{\star}$ STAR, Singapore

* Corresponding authors (emails: chengy@ihpc.a-star.edu.sg (Cheng Y); jbli@semi.ac.cn (Li J))
} 
reduced interfacial recombination and improved interface binding in PSCs by $\mathrm{TiO}_{2} /$ perovskite interface passivation with chlorine. Jiang et al. [14] found that non-radiative recombination can be suppressed by surface defect passivation with an organic halide salt phenethylammonium iodide. Chen et al. [31] demonstrated that $\mathrm{PbI}_{2}$ phase formed at the perovskite grain boundaries and relevant interfaces can function as self-induced passivation of LHPs and improve the performance of solar cells. Busby et al. [43] provided experimental studies on the interface and composition effect in PSCs [41,42]. Their further work demonstrated that the stability of PSCs can be well improved by interface engineering with two-dimensional (2D) nano-materials.

Although some experimental studies have demonstrated that interface treatments with various materials can be helpful to improve the performance of PSCs, the nature of these treatments is not well understood. Taking LHP/ETL interface as an example, a good treatment material between absorber and transport layer should satisfy several requirements. i) The treatment material has good defect properties and does not introduce deep defect states. ii) It should have suitable band alignment with the LHP absorber and ETL layers to transport electrons efficiently and hinder the hole transport. iii) It should be able to passivate the pre-existing deep interfacial states. iv) The growth of the buffer material should be easy and controllable in experiments. As shown in Fig. 1a, when there is a high density of deep interfacial states, the Fermi level will be pinned by these interfacial states. Consequently, the band bending and $V_{\mathrm{OC}}$ are rather small without a p-to-n type inversion of the absorber. With a buffer layer being added between the absorber and ETL, the deep interfacial states are expected to be passivated, as shown in Fig. 1b. As a result, the band bending at the interface and $V_{\mathrm{OC}}$ can be significantly enhanced with an effective p-to-n type inversion. Therefore, the formation of deep interfacial states must be suppressed to make the type inversion possible at the interface, in order to overcome the $V_{\mathrm{OC}}$ deficit of PSCs.

Herein, we performed a theoretical study on the effect of the treatment at the absorber/ETL interface on the performance of corresponding solar cells. $\mathrm{MAPbI}_{3}$ and $\mathrm{TiO}_{2}$ are employed here as typical LHP absorber and ETL. Four possible secondary phase including MAI, MACl, $\mathrm{PbI}_{2}$ and $\mathrm{PbCl}_{2}$ are employed in this work to study their effects as buffer layer materials between LHP absorber $\left(\mathrm{MAPbI}_{3}\right)$ and ETL (rutile $\mathrm{TiO}_{2}$ ) on the electronic properties of interfaces. Our results of band alignments indicate that $\mathrm{MACl}$ and MAI can create high electron
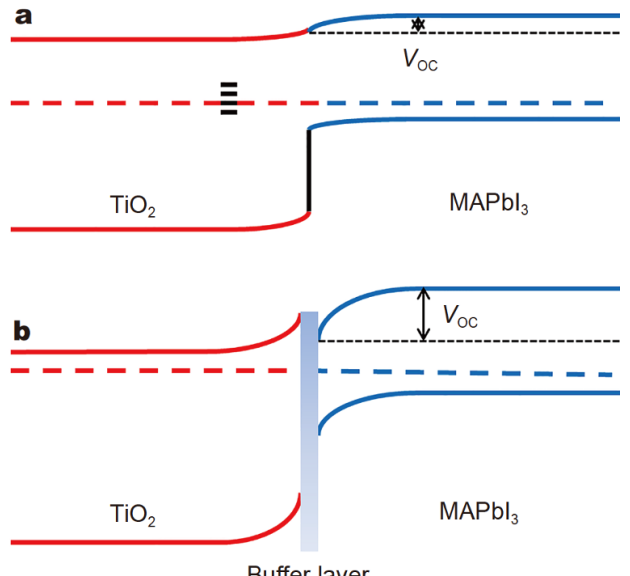

Figure 1 The band diagram of LHP absorber/ETL interface. (a) The $\mathrm{TiO}_{2} / \mathrm{MAPbI}_{3}$ solar cell with a high density of deep states at the interface. The Fermi level near the interface is pinned by these deep states and small band bending in the absorber layer. (b) $\mathrm{The}^{\mathrm{TiO}} \mathrm{M}_{2} / \mathrm{MAPbI}_{3}$ solar cell with an ideal buffer layer between $\mathrm{TiO}_{2}$ and $\mathrm{MAPbI}_{3}$. Deep surface states are passivated and a large band bending is obtained in the absorber layer.

barriers and reduce the electron collection efficiency of ETL. The conduction band minimum (CBM) of $\mathrm{PbI}_{2}$ is much lower than that of $\mathrm{MAPbI}_{3}$, which significantly limits the near-interface band bending of absorber and $V_{\mathrm{OC}}$ of PSCs. $\mathrm{PbCl}_{2}$ is demonstrated to be a good buffer material for LHP/ETL interface engineering with suitable band alignments and good interfacial defect passivation effect.

\section{COMPUTATIONAL METHODS}

All calculations were performed in the VASP code using the projector augmented plane-wave method [44-46]. In structural relaxation and total energy calculation, the general gradient approximation (GGA) of Perdew, Burke and Ernzerhof (PBE) [47,48] was adopted. The planewave cutoff energy was set as $500 \mathrm{eV}$ in all the calculations. To eliminate the interaction between adjacent slabs, a vacuum larger than $15 \AA$ was used. All the structures were fully relaxed with a force tolerance of $0.02 \mathrm{eV} \AA^{-1}$. DFT-D3 method of Grimme [49] was used to correct the van der Waals (vdW) interaction in $\mathrm{MAPbI}_{3}$ and at interfaces.

$\mathrm{MAPbI}_{3}$ in $\alpha$-phase was employed in this work. Two different $\mathrm{MAPbI}_{3}$ (001) surfaces, MAI-terminated and $\mathrm{PbI}_{2}$-terminated, were taken into consideration. The formation energies of these two $\mathrm{MAPbI}_{3}$ surfaces with their thickness of three layers were calculated to evaluate their relative stability. For MAI-terminated and $\mathrm{PbI}_{2}{ }^{-}$ terminated $\mathrm{MAPbI}_{3}$ surfaces, the formation energies were 
respectively calculated as [50]

$E_{f}\left(\mathrm{MA}_{4} \mathrm{~Pb}_{3} \mathrm{I}_{10}\right)=\left[E_{\text {slab }}-4 E_{\mathrm{MAI}}-3 E_{\mathrm{PbI}_{2}}\right] / 3$,

$E_{f}\left(\mathrm{MA}_{3} \mathrm{~Pb}_{4} \mathrm{I}_{11}\right)=\left[E_{\text {slab }}-3 E_{\mathrm{MAI}}-4 E_{\mathrm{PbI}_{2}}\right] / 3$.

The band alignments were calculated by using corelevel alignment, as described in Refs [51,52]. Taking $\mathrm{TiO}_{2}$ and MAI as examples, the energy difference between the core level and the VBM in bulk $\mathrm{TiO}_{2}$ and MAI $\left(\Delta E_{c, V}^{\mathrm{TiO}_{2}}\right.$ and $\Delta E_{c, V}^{\mathrm{MAI}}$ ) were calculated firstly. Then we did the corelevel alignment in $\mathrm{TiO}_{2} / \mathrm{MAI}$ superlattice and obtained the core-level difference, $\Delta E_{c, c}$. Then the valence band offset, $\Delta E_{V}$, was calculated as

$$
\Delta E_{V}=\Delta E_{c, V}^{\mathrm{TiO}_{2}}-\Delta E_{c, V}^{\mathrm{MAI}}+\Delta E_{c, c} \text {. }
$$

The conduction band offset was calculated as $\Delta E_{C}=E_{g}^{\mathrm{TiO}_{2}}-E_{g}^{\mathrm{MAI}}+\Delta E_{V}$.

\section{RESULTS AND DISCUSSION}

Previous studies have demonstrated that LHPs prefer to make contacts with $\mathrm{TiO}_{2}$ (112) surface $[9,53,54]$. So $\mathrm{TiO}_{2}$ slabs in this work were built by cutting $\mathrm{TiO}_{2}$ through (112) surface. Fig. 2 shows the crystal structures of (a) $\mathrm{TiO}_{2}$ (112) surface, (b) MAI-terminated and (c) $\mathrm{PbI}_{2}-$ terminated $\mathrm{MAPbI}_{3}$ (001) surface. We calculated the formation energies of both types of $\mathrm{MAPbI}_{3}$ slabs to discuss their thermodynamic stability. Their negative formation energies indicate that both MAI-terminated and $\mathrm{PbI}_{2}$-terminated can be thermodynamically stable. It is also found that MAI-terminated $\mathrm{MAPbI}_{3}$ slab has a lower formation energy $(-0.70 \mathrm{eV})$ than $\mathrm{PbI}_{2}$-terminated one $(-0.54 \mathrm{eV})$, which is consistent with pervious work [49]. This is attributed to the stronger bonding between I and $\mathrm{Pb}$ atoms than MA-I bonding. As a result, it costs more energy to break the $\mathrm{Pb}-\mathrm{I}$ bonds to form $\mathrm{PbI}_{2}$-terminated $\mathrm{MAPbI}_{3}$ surface.

Though MAI-terminated $\mathrm{MAPbI}_{3}$ surface is more energetically favorable than $\mathrm{PbI}_{2}$-terminated one, the contact surface of $\mathrm{MAPbI}_{3}$ to $\mathrm{TiO}_{2}$ can be controlled by varying the chemical potentials of related elements in experiments. Actually, it has been demonstrated that $\mathrm{TiO}_{2}$ (112) makes better contact to $\mathrm{PbI}_{2}$-terminated $\mathrm{MAPbI}_{3}$ (001) surface $[9,50]$.

Before discussing the band alignments between buffer layer and $\mathrm{MAPbI}_{3}$ absorber, we explored the layer-dependent bandedge positions of $\mathrm{MAPbI}_{3}$ slabs in Fig. 3 . Since GGA-PBE functional gives correct description on the variation of bandedges, spin-orbital coupling (SOC) and hybrid functional corrections were not considered

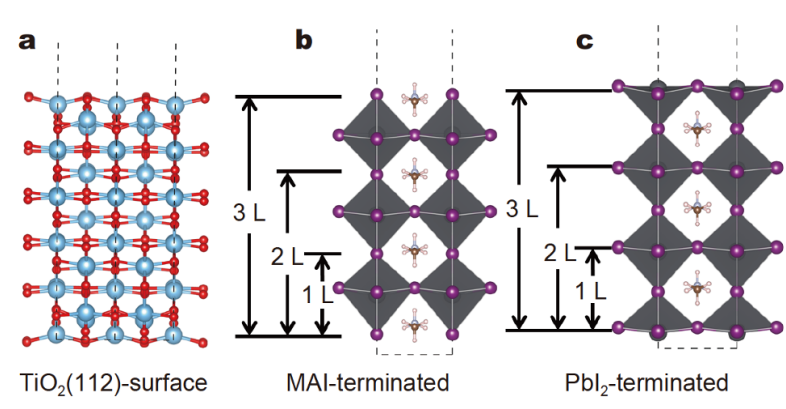

Figure 2 The crystal structures of (a) $\mathrm{TiO}_{2}$ (112) surface, (b) MAIterminated and (c) $\mathrm{PbI}_{2}$-terminated $\mathrm{MAPbI}_{3}$ (001) surfaces from side view. The number of layers of $\mathrm{MAPbI}_{3}$ slabs is labeled.
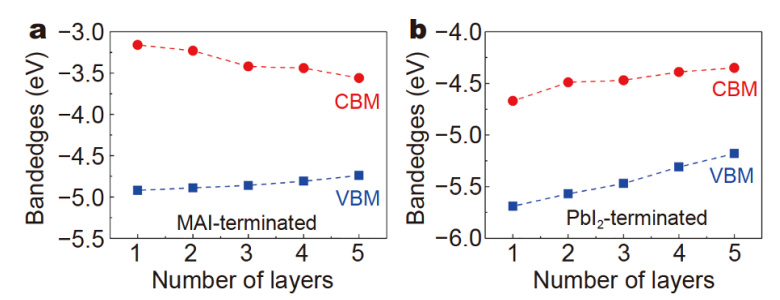

Figure 3 Layer-dependent bandedge positions of (a) MAI-terminated and (b) $\mathrm{PbI}_{2}$-terminated $\mathrm{MAPbI}_{3}$ slabs. The vacuum level is taken as reference.

here. The vacuum level was taken as reference in calculations of the bandedges of $\mathrm{MAPbI}_{3}$ slabs. It is found from Fig. 3 that bandedges of both MAI-terminated and $\mathrm{PbI}_{2}$ terminated $\mathrm{MAPbI}_{3}$ slabs show significant dependence on the thickness of slabs. Specifically, in the case of MAIterminated $\mathrm{MAPbI}_{3}$ slab, its CBM decreases and its valence band maximum (VBM) increases with the number of layers, resulting in reduced band gap when its thickness increases. While both the CBM and $\mathrm{VBM}$ of $\mathrm{PbI}_{2}^{-}$ terminated $\mathrm{MAPbI}_{3}$ slab increase with the number of layers, which is accompanied by its decreasing band gap. This band gap variation shows similar trend to the $2 \mathrm{D}$ LHPs in Ruddlesden-Poper phases and low-dimensional LHPs $[55,56]$.

We then discuss the influence of interfacial buffer layer on the carrier transport properties. Considering the feasibility in experiments and device designing, four semiconducting materials, $\mathrm{MAI}, \mathrm{MACl}, \mathrm{PbCl}_{2}$ and $\mathrm{PbI}_{2}$, were employed as the buffer layer. The band alignments between $\mathrm{TiO}_{2}$ and $\mathrm{MAPbI}_{3}$ were corrected by referring to the experimental value of conduction band offset $(0.40 \mathrm{eV})$. Here the bandedge positions of these buffer materials were calculated on GGA-PBE level, and the bandedges of $\mathrm{TiO}_{2}$ are adopted as references.

Band alignments in Fig. 4 show that all these four buffer materials will introduce hole barriers between $\mathrm{TiO}_{2}$ 


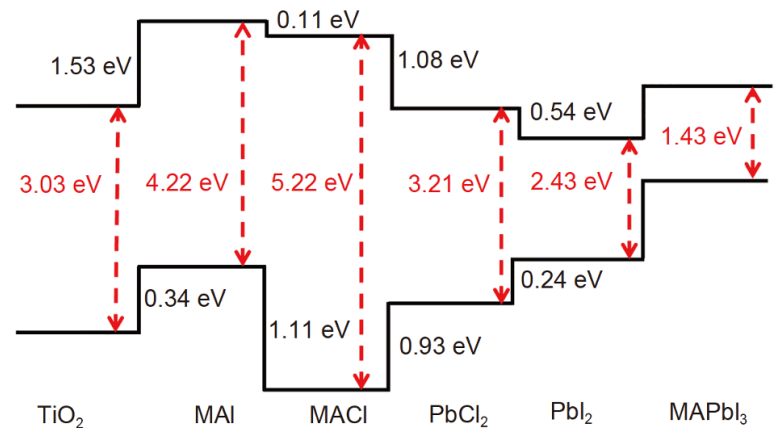

Figure 4 Schematic bandedge energy level positions of $\mathrm{TiO}_{2}, \mathrm{MAPbI}_{3}$ and four buffer materials (MAI, MACl, $\mathrm{PbCl}_{2}$ and $\mathrm{PbI}_{2}$ ). The conduction band offset between $\mathrm{TiO}_{2}$ and $\mathrm{MAPbI}_{3}$ is taken as experimental value. Band alignments here are calculated by using the core-level alignment approach.

and $\mathrm{MAPbI}_{3}$, suggesting that holes in $\mathrm{MAPbI}_{3}$ absorber will be reflected by the buffer layer. At the absorber/ETL interface, the conduction band offset is of much more importance. The CBM energy position of a suitable buffer material should between the CBM energy positions of the absorber and ETL to facilitate electron transportation. Our results in Fig. 4 indicate that MAI and $\mathrm{MACl}$ will introduce electron barriers between $\mathrm{MAPbI}_{3}$ and $\mathrm{TiO}_{2}$, which is detrimental for electron transportation from $\mathrm{MAPbI}_{3}$ absorber to $\mathrm{TiO}_{2}$. This means electron-hole recombination in $\mathrm{MAPbI}_{3}$ will be enhanced and PCE of corresponding PSCs will be reduced. Our results suggest that MAI and $\mathrm{MACl}$ are not suitable buffer materials.

In the case of $\mathrm{PbI}_{2}$, its much lower CBM than that of $\mathrm{MAPbI}_{3}$ makes it unsuitable buffer material in lead iodides PSCs, even though this could be helpful for electron collection. The Fermi level of $\mathrm{PbI}_{2} / \mathrm{MAPbI}_{3}$ interface can not be higher than the $\mathrm{CBM}$ of $\mathrm{PbI}_{2}$. As a result, the band bending of $\mathrm{MAPbI}_{3}$ in the near-interface region and $V_{\mathrm{OC}}$ are severely limited. On the other hand, holes from $\mathrm{MAPbI}_{3}$ absorber can be trapped by the CBM states of $\mathrm{PbI}_{2}$, improving the electron-hole recombination at the interface.

In the view of band alignments, $\mathrm{PbCl}_{2}$ is a good buffer layer with its CBM between the CBMs of $\mathrm{TiO}_{2}$ and $\mathrm{MAPbI}_{3}$ and much lower $\mathrm{VBM}$ than $\mathrm{MAPbI}_{3}$. These results suggest that a buffer layer $\mathrm{PbCl}_{2}$ can facilitate the electron transport and reflect holes from the $\mathrm{MAPbI}_{3}$ absorber. So the LHP absorber should be grown under a $\mathrm{PbX}_{2}$-rich $(\mathrm{X}=\mathrm{Cl}, \mathrm{Br}, \mathrm{I})$ condition to form a $\mathrm{PbCl}_{2}$ buffer layer at the LHP/ETL interface. What's more, it is demonstrated that the formation energy of $\mathrm{MAPbI}_{3}$ slab depends on the chemical potentials of $\mathrm{PbI}_{2}$ and MAI [21]. Under $\mathrm{PbI}_{2}$-rich condition, which means $\mathrm{Pb}$ and $\mathrm{I}$ have high chemical potentials, $\mathrm{PbI}_{2}$-terminated $\mathrm{MAPbI}_{3}$ surface has a lower formation energy than the case of MAIrich condition. So $\mathrm{PbX}_{2}$-rich condition also promotes the formation of $\mathrm{PbX}_{2}$-terminated LHP surfaces.

It seems that the values given in Fig. 4 are different from the experimentally measured ones, which mainly comes from the underestimation in bandgaps in GGAPBE functional calculation. While the general features of band alignments in Fig. 4 are well predicted, further support to the rationality of results in Fig. 4 can be obtained from orbital coupling analysis. For example, CBMs of MACl and MAI are mainly composed by s orbital of MA molecule. So they should have similar CBM positions with small conduction band offset. On the other side, the large difference in the VBMs of $\mathrm{MACl}$ and MAI is caused by the large energy difference between $\mathrm{Cl} \mathrm{p}$ and $\mathrm{I} \mathrm{p}$ orbitals. Similar trends also are observed in $\mathrm{PbCl}_{2} / \mathrm{PbI}_{2}$. Because the VBMs of $\mathrm{PbCl}_{2}$ and $\mathrm{PbI}_{2}$ mainly consist of the antibonding states of $\mathrm{Pb}$ s and $\mathrm{X} \mathrm{p}(\mathrm{X}=\mathrm{Cl}, \mathrm{I})$ orbitals, the valence band offset in $\mathrm{PbCl}_{2} / \mathrm{PbI}_{2}$ is much smaller than that of $\mathrm{MACl} / \mathrm{MAI}$. The antibonding coupling in $\mathrm{PbX}_{2}$ is also responsible for the higher conduction band positions than MAX. According to the analysis above, Fig. 4 gives correct description on the band alignments of materials employed in this work, even though the absolute values of bandgap are underestimated.

Further insights into the band alignments can be obtained from the interfacial charge density difference of $\mathrm{TiO}_{2}$ /buffer-layer (Fig. 5). The yellow and blue areas indicate electron accumulation and depletion, respectively.

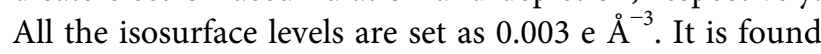
in Fig. $5 \mathrm{a}$ and $\mathrm{b}$ that electrons tend to transfer from the MAX $\left(\mathrm{X}=\mathrm{Cl}\right.$, I) buffer layer to $\mathrm{TiO}_{2}$ at $\mathrm{MAX} / \mathrm{TiO}_{2}$ interfaces, suggesting a lower $\mathrm{CBM}$ of $\mathrm{TiO}_{2}$. In the case of $\mathrm{PbCl}_{2} / \mathrm{TiO}_{2}$ interface (Fig. $5 \mathrm{c}$ ), the net exchange carrier between $\mathrm{PbCl}_{2}$ and $\mathrm{TiO}_{2}$ is too small to identify from the interfacial charge density difference, which means a small difference in their CBM positions. For $\mathrm{PbI}_{2} / \mathrm{TiO}_{2}$ interface, the charge exchange between $\mathrm{PbI}_{2}$ and $\mathrm{TiO}_{2}$ is much weaker compared with the other three interfaces. This is attributed to the layered structure and vdW interlayer coupling of $\mathrm{PbI}_{2}$.

As illustrated in Fig. 1, a good buffer layer at the LHPabsorber/ETL interface not only has suitable band alignments with the absorber and ETL materials, but also passivates the pre-existing deep interfacial states. Before discussing the passivation effect of the buffer layer, we explored the electronic structures of $\mathrm{TiO}_{2}$ (112) surface in Fig. 6 and $\mathrm{MAPbI}_{3}$ (001) surfaces in Fig. 7. Projected density of states (PDOS) of $\mathrm{TiO}_{2}$ and $\mathrm{MAPbI}_{3}$ surfaces are 

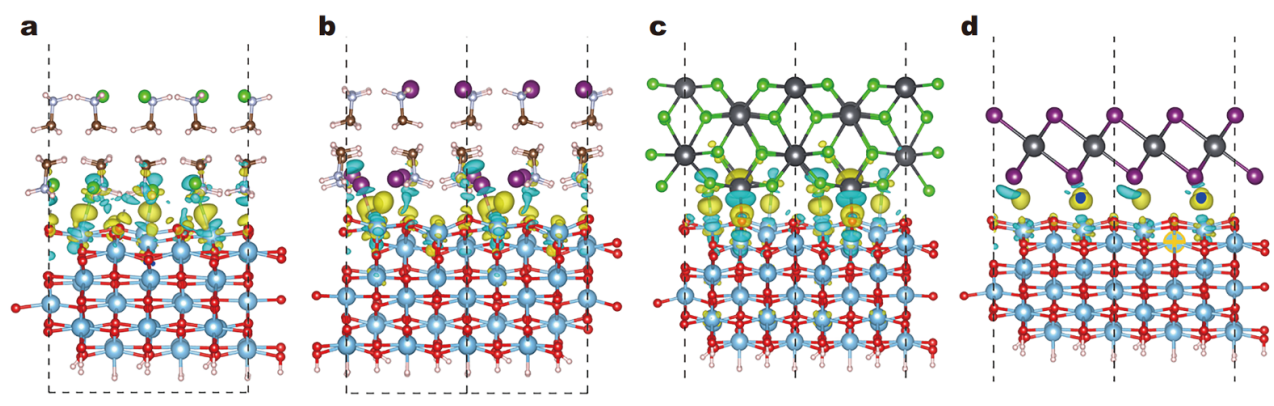

Figure 5 Charge density difference at interfaces between $\mathrm{TiO}_{2}$ and (a) $\mathrm{MACl}$, (b) $\mathrm{MAI}$, (c) $\mathrm{PbCl}_{2}$, and (d) $\mathrm{PbI}_{2}$. The yellow and blue areas indicate electron accumulation and depletion, respectively. All the isosurface levels are set as $0.003 \mathrm{e} \AA^{-3}$.

calculated in Figs 6 and 7, respectively, with resolved contribution of each type of ion to PDOS. It can be seen from Fig. $6 a$ and $b$ that the VBM and CBM of $\mathrm{TiO}_{2}$ mainly consist of $\mathrm{O} p$ orbitals and $\mathrm{Ti} \mathrm{d}$ orbitals, respectively [53]. When bulk $\mathrm{TiO}_{2}$ is cut through (112) surface, defect states are generated near its VBM due to the broken Ti-O bonds at the surface.

Many previous studies have demonstrated that the CBMs of LHPs are mainly contributed by non-bonding $\mathrm{Pb} \mathrm{p}$ states and their VBMs mainly consist of the antibonding states between $\mathrm{p}$ orbitals of halide atoms and $\mathrm{Pb}$ $\mathrm{s}$ orbtial $[21,53]$. In $\mathrm{MAPbI}_{3}, \mathrm{MA}^{+}$contributes little to the bandedges of $\mathrm{MAPbI}_{3}$. As a result, there are nearly no deep surface states in the MAI-terminated $\mathrm{MAPbI}_{3}$ surface. While in the case of $\mathrm{PbI}_{2}$-terminated $\mathrm{MAPbI}_{3}$ surface, which is usually the case in experiments, $\mathrm{MA}^{+}$does not introduce gap states because its orbitals are distributed in high conduction bands and low valence bands, as shown in Fig. 7c. Compared with PDOS of MAI-terminated $\mathrm{MAPbI}_{3}$ surface, the broken $\mathrm{Pb}-\mathrm{I}$ bonds at $\mathrm{PbI}_{2}-$ terminated $\mathrm{MAPbI}_{3}$ surface create a high density of gap states near the CBM and $\mathrm{VBM}$ of $\mathrm{MAPbI}_{3}$, as shown in Fig. $7 \mathrm{a}$ and b. Since $\mathrm{MAPbI}_{3}$ is intrinsically a p-type semiconductor, shallow defects near the VBM can be helpful to increase the density of holes. The shallow defects near the CBM, however, are detrimental to the concentration and life-time of holes, which further reduces the PCEs of solar cells.

Interfacial defect passivation through adding a buffer layer is an useful route for further increasing the PCE and the $V_{\mathrm{OC}}$ of the PSCs. In Fig. 8, we discuss the interfacial passivation effect of the above four buffer materials by calculating the PDOS on $\mathrm{Ti}$ and $\mathrm{O}$ atoms of $\mathrm{TiO}_{2} / \mathrm{MACl}$ (Fig. 8a), $\mathrm{TiO}_{2} / \mathrm{MAI}$ (Fig. 8b), $\mathrm{TiO}_{2} / \mathrm{PbCl}_{2}$ (Fig. 8c) and $\mathrm{TiO}_{2} / \mathrm{PbI}_{2}$ (Fig. 8d). It is found that defect states at the $\mathrm{TiO}_{2}$ (112) surface can not be fully passivated by MAX (X $=\mathrm{Cl}, \mathrm{I})$. There is still a high density of surface states above
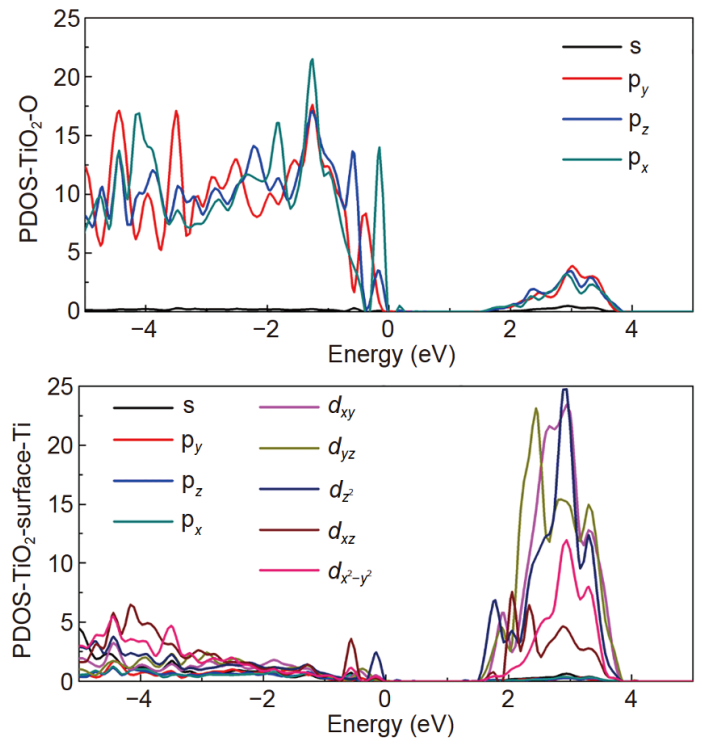

Figure 6 PDOS of $\mathrm{TiO}_{2}$ (112) surface. (a) and (b) are the PDOS contributed by $\mathrm{O}$ and $\mathrm{Ti}$ atoms, respectively.

the $\mathrm{VBM}$ of $\mathrm{TiO}_{2}$. Especially at the $\mathrm{MAI} / \mathrm{TiO}_{2}$ interface, some extra deep interfacial states are introduced due to large lattice mismatch between $\mathrm{MAI}$ and $\mathrm{TiO}_{2} \cdot \mathrm{PbI}_{2}$ has a weak influence on the electronic structure of $\mathrm{TiO}_{2}$ surface due to the weak vdW interfacial coupling.

Fortunately, $\mathrm{PbCl}_{2}$, which has suitable band alignments with $\mathrm{TiO}_{2}$ and $\mathrm{MAPbI}_{3}$, exhibits the best surface passivation effect. Two main reasons are responsible for this. Firstly, the lattice mismatch between $\mathrm{PbCl}_{2}$ and $\mathrm{TiO}_{2}$ is very small so that the concentration of dangling bonds is low. Secondly, the interfacial coupling between $\mathrm{PbCl}_{2}$ and $\mathrm{TiO}_{2}$ is strong so that the dangling bonds at the $\mathrm{TiO}_{2}$ surface are well passivated. Theoretically, the strength of coupling between two states is proportional to the overlap of their wavefunctions. And the wavefunction overlap depends on the atomic distance between the involved two 
a

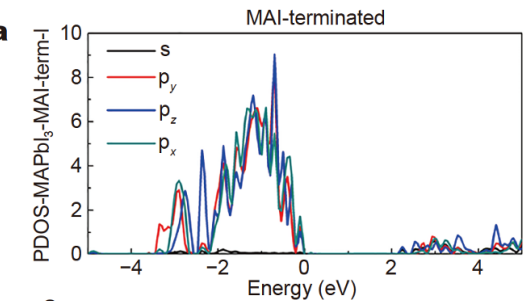

b
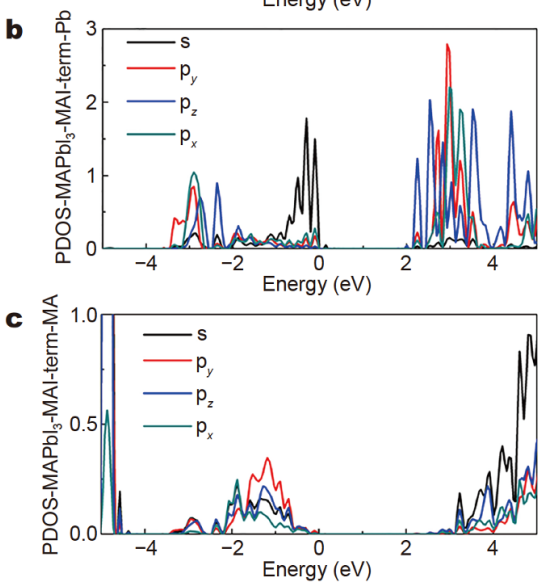
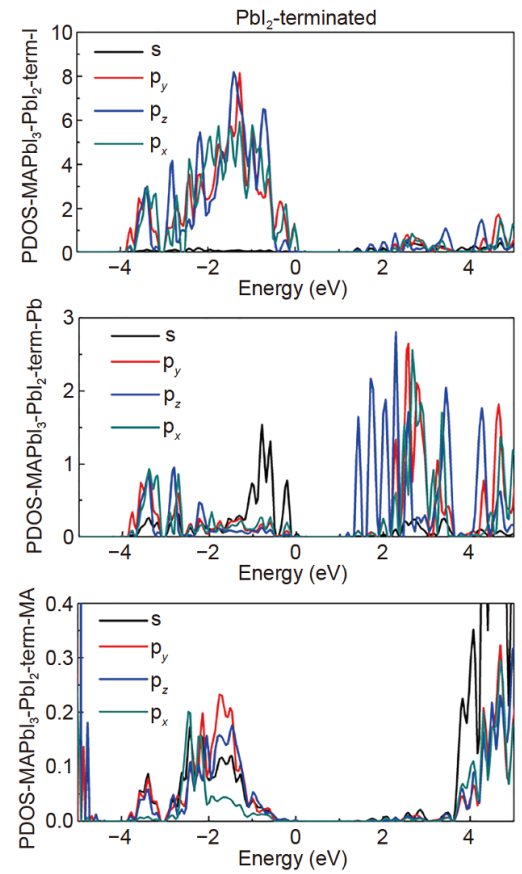

Figure 7 PDOS of MAI-terminated (left side) and $\mathrm{PbI}_{2}$-terminated (right side) $\mathrm{MAPbI}_{3}$ (001) surfaces. (a), (b) and (c) are PDOS contributed by I, Pb and MA ions, respectively.
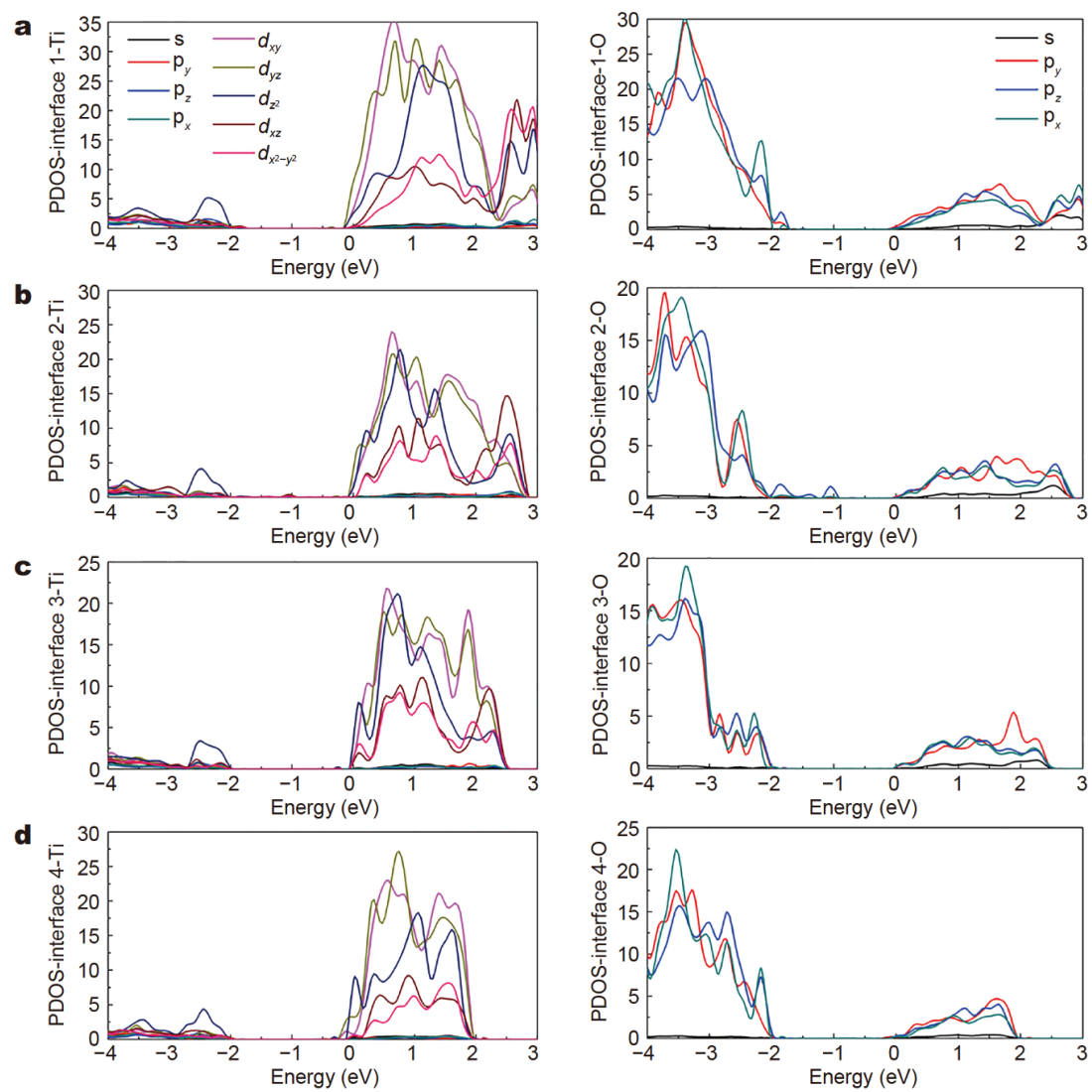

Figure $8 \mathrm{PDOS}$ on $\mathrm{Ti}$ (left side) and $\mathrm{O}$ (right side) atoms in interfaces of (a) $\mathrm{TiO}_{2} / \mathrm{MACl}(\mathrm{b}) \mathrm{TiO}_{2} / \mathrm{MAI}(\mathrm{c}) \mathrm{TiO}_{2} / \mathrm{PbCl}_{2}$ and (d) $\mathrm{TiO}_{2} / \mathrm{PbI}_{2}$. 
atoms. Due to the shorter bond length of Ti-Cl than Ti-I, $\mathrm{PbCl}_{2}$ can couple with $\mathrm{TiO}_{2}$ stronger than $\mathrm{PbI}_{2}$. Strong interfacial coupling usually means large energy gain upon two materials binding together. So in some $(\mathrm{Cl}, \mathrm{I})$ alloyed LHPs, $\mathrm{PbCl}_{2}$-terminated surface may be energetically more favorable than $\mathrm{PbI}_{2}$-terminated one. Fig. $5 \mathrm{c}$ provides clear insights into the interfacial coupling of $\mathrm{TiO}_{2} /$ $\mathrm{PbCl}_{2}$. Obvious charge exchange is observed. Surface states caused by dangling bonds of $\mathrm{Ti}$ and $\mathrm{O}$ atoms coupled well with $\mathrm{Cl}$ and $\mathrm{Pb}$ atoms of $\mathrm{PbCl}_{2}$, respectively. It is concluded that $\mathrm{PbCl}_{2}$ is a good buffer layer material for interface engineering between the LHP absorber and ETL.

\section{CONCLUSION}

In conclusion, first-principles calculations were performed to explore the effect of four candidate buffer materials ( $\mathrm{MACl}, \mathrm{MAI}, \mathrm{PbCl}_{2}$ and $\mathrm{PbI}_{2}$ ) on the electronic structures of interface between the $\mathrm{MAPbI}_{3}$ absorber and $\mathrm{TiO}_{2}$. Our results of band alignments indicate that MAX $(\mathrm{X}=\mathrm{Cl}, \mathrm{I})$ as buffer layers will introduce a high electron barrier which reduces the electron collection efficiency of ETL. Electron-hole recombination will be enhanced and the PCEs of solar cells will be reduced. Additionally, MAX are not able to well passivate the surface states. The $\mathrm{CBM}$ of $\mathrm{PbI}_{2}$ is much lower than that of $\mathrm{MAPbI}_{3}$ absorber, which significantly limits the band bending of the absorber and $V_{\mathrm{OC}}$ of PSCs. Furthermore, its layered crystal structure and weak vdW interfacial coupling reduce its surface passivation effect on the $\mathrm{TiO}_{2}$ surface. Most importantly, suitable bandedge energy level positions, small lattice mismatch with $\mathrm{TiO}_{2}$ (112) surface, and excellent surface passivation effect make $\mathrm{PbCl}_{2}$ a promising buffer material for LHPs/ETL interface engineering in PSCs.

Received 28 January 2019; accepted 31 March 2020; published online 30 April 2020

1 Kojima A, Teshima K, Shirai Y, et al. Organometal halide perovskites as visible-light sensitizers for photovoltaic cells. J Am Chem Soc, 2009, 131: 6050-6051

2 Kim HS, Lee CR, Im JH, et al. Lead iodide perovskite sensitized allsolid-state submicron thin film mesoscopic solar cell with efficiency exceeding 9\%. Sci Rep, 2012, 2: 591

3 Lee MM, Teuscher J, Miyasaka T, et al. Efficient hybrid solar cells based on meso-superstructured organometal halide perovskites. Science, 2012, 338: 643-647

4 Zhou H, Chen Q, Li G, et al. Interface engineering of highly efficient perovskite solar cells. Science, 2014, 345: 542-546

5 Jeon NJ, Noh JH, Yang WS, et al. Compositional engineering of perovskite materials for high-performance solar cells. Nature, 2015, 517: $476-480$
6 Nie W, Tsai H, Asadpour R, et al. High-efficiency solution-processed perovskite solar cells with millimeter-scale grains. Science, 2015, 347: 522-525

7 Bi D, Yi C, Luo J, et al. Polymer-templated nucleation and crystal growth of perovskite films for solar cells with efficiency greater than 21\%. Nat Energy, 2016, 1: 16142

8 Jiang $\mathrm{Q}$, Zhang L, Wang $\mathrm{H}$, et al. Enhanced electron extraction using $\mathrm{SnO}_{2}$ for high-efficiency planar-structure $\mathrm{HC}\left(\mathrm{NH}_{2}\right)_{2} \mathrm{PbI}_{3^{-}}$ based perovskite solar cells. Nat Energy, 2016, 2: 16177

9 Tan H, Jain A, Voznyy O, et al. Efficient and stable solutionprocessed planar perovskite solar cells via contact passivation. Science, 2017, 355: 722-726

10 Anaraki EH, Kermanpur A, Steier L, et al. Highly efficient and stable planar perovskite solar cells by solution-processed tin oxide. Energy Environ Sci, 2016, 9: 3128-3134

11 Zheng X, Chen B, Dai J, et al. Defect passivation in hybrid perovskite solar cells using quaternary ammonium halide anions and cations. Nat Energy, 2017, 2: 17102

12 Yang WS, Park BW, Jung EH, et al. Iodide management in formamidinium-lead-halide-based perovskite layers for efficient solar cells. Science, 2017, 356: 1376-1379

13 Green MA, Hishikawa Y, Dunlop ED, et al. Solar cell efficiency tables (version 51). Prog Photovolt Res Appl, 2018, 26: 3-12

14 Jiang Q, Zhao Y, Zhang X, et al. Surface passivation of perovskite film for efficient solar cells. Nat Photonics, 2019, 13: 460-466

15 Wang Q, Dong Q, Li T, et al. Thin insulating tunneling contacts for efficient and water-resistant perovskite solar cells. Adv Mater, 2016, 28: 6734-6739

16 Buin A, Pietsch P, Xu J, et al. Materials processing routes to trapfree halide perovskites. Nano Lett, 2014, 14: 6281-6286

17 Yuan ZK, Chen S, Xiang H, et al. Engineering solar cell absorbers by exploring the band alignment and defect disparity: The case of $\mathrm{Cu}$ - and Ag-based kesterite compounds. Adv Funct Mater, 2015, 25: 6733-6743

18 Würfel P. Physics of Solar Cells. Weinheim: Wiley-VCH, 2007, Ch. 6

19 Chirilă A, Buecheler S, Pianezzi F, et al. Highly efficient $\mathrm{Cu}(\mathrm{In}, \mathrm{Ga}) \mathrm{Se}_{2}$ solar cells grown on flexible polymer films. Nat Mater, 2011, 10: 857-861

20 Liu $\mathrm{Z}, \mathrm{Hu}$ J, Jiao $\mathrm{H}$, et al. Chemical reduction of intrinsic defects in thicker heterojunction planar perovskite solar cells. Adv Mater, 2017, 29: 1606774

21 Yin WJ, Shi T, Yan Y. Unusual defect physics in $\mathrm{CH}_{3} \mathrm{NH}_{3} \mathrm{PbI}_{3}$ perovskite solar cell absorber. Appl Phys Lett, 2014, 104: 063903

22 Yin WJ, Yang JH, Kang J, et al. Halide perovskite materials for solar cells: a theoretical review. J Mater Chem A, 2015, 3: 89268942

23 Zhang Q, Su R, Liu X, et al. High-quality whispering-gallery-mode lasing from cesium lead halide perovskite nanoplatelets. Adv Funct Mater, 2016, 26: 6238-6245

24 Wojciechowski K, Stranks SD, Abate A, et al. Heterojunction modification for highly efficient organic-inorganic perovskite solar cells. ACS Nano, 2014, 8: 12701-12709

25 Li Y, Zhao Y, Chen Q, et al. Multifunctional fullerene derivative for interface engineering in perovskite solar cells. J Am Chem Soc, 2015, 137: 15540-15547

26 Yang D, Zhou X, Yang R, et al. Surface optimization to eliminate hysteresis for record efficiency planar perovskite solar cells. Energy Environ Sci, 2016, 9: 3071-3078

27 Christians JA, Schulz P, Tinkham JS, et al. Tailored interfaces of unencapsulated perovskite solar cells for $>1,000$ hour operational 
stability. Nat Energy, 2018, 3: 68-74

28 Correa Baena JP, Steier L, Tress W, et al. Highly efficient planar perovskite solar cells through band alignment engineering. Energy Environ Sci, 2015, 8: 2928-2934

29 Zu FS, Amsalem P, Salzmann I, et al. Impact of white light illumination on the electronic and chemical structures of mixed halide and single crystal perovskites. Adv Opt Mater, 2017, 5: 1700139

30 Schulz P, Cahen D, Kahn A. Halide perovskites: Is it all about the interfaces? Chem Rev, 2019, 119: 3349-3417

31 Chen Q, Zhou H, Song TB, et al. Controllable self-induced passivation of hybrid lead iodide perovskites toward high performance solar cells. Nano Lett, 2014, 14: 4158-4163

32 Wang L, McCleese C, Kovalsky A, et al. Femtosecond time-resolved transient absorption spectroscopy of $\mathrm{CH}_{3} \mathrm{NH}_{3} \mathrm{PbI}_{3}$ perovskite films: Evidence for passivation effect of $\mathrm{PbI}_{2}$. J Am Chem Soc, 2014, 136: 12205-12208

33 Cho KT, Paek S, Grancini G, et al. Highly efficient perovskite solar cells with a compositionally engineered perovskite/hole transporting material interface. Energy Environ Sci, 2017, 10: 621-627

34 Shang Q, Wang Y, Zhong Y, et al. Unveiling structurally engineered carrier dynamics in hybrid quasi-two-dimensional perovskite thin films toward controllable emission. J Phys Chem Lett, 2017, 8: 4431-4438

35 Chen P, Bai Y, Wang S, et al. In situ growth of 2D perovskite capping layer for stable and efficient perovskite solar cells. Adv Funct Mater, 2018, 28: 1706923

36 Cho Y, Soufiani AM, Yun JS, et al. Mixed 3D-2D passivation treatment for mixed-cation lead mixed-halide perovskite solar cells for higher efficiency and better stability. Adv Energy Mater, 2018, 8: 1703392

37 Cho KT, Grancini G, Lee Y, et al. Selective growth of layered perovskites for stable and efficient photovoltaics. Energy Environ Sci, 2018, 11: 952-959

38 Yoo HS, Park NG. Post-treatment of perovskite film with phenylalkylammonium iodide for hysteresis-less perovskite solar cells. Sol Energy Mater Sol Cells, 2018, 179: 57-65

39 Li N, Zhu Z, Dong Q, et al. Enhanced moisture stability of cesiumcontaining compositional perovskites by a feasible interfacial engineering. Adv Mater Interfaces, 2017, 4: 1700598

40 Li C, Liu Z, Shang Q, et al. Surface-plasmon-assisted metal halide perovskite small lasers. Adv Opt Mater, 2019, 7: 1900279

41 Matteocci F, Busby Y, Pireaux JJ, et al. Interface and composition analysis on perovskite solar cells. ACS Appl Mater Interfaces, 2015, 7: 26176-26183

42 Ralaiarisoa M, Busby Y, Frisch J, et al. Correlation of annealing time with crystal structure, composition, and electronic properties of $\mathrm{CH}_{3} \mathrm{NH}_{3} \mathrm{PbI}_{3-x} \mathrm{Cl}_{x}$ mixed-halide perovskite films. Phys Chem Chem Phys, 2017, 19: 828-836

43 Busby Y, Agresti A, Pescetelli S, et al. Aging effects in interfaceengineered perovskite solar cells with 2D nanomaterials: A depth profile analysis. Mater Today Energy, 2018, 9: 1-10

44 Blöchl PE. Projector augmented-wave method. Phys Rev B, 1994, 50: $17953-17979$
45 Kresse G, Joubert D. From ultrasoft pseudopotentials to the projector augmented-wave method. Phys Rev B, 1999, 59: 1758-1775

46 Kresse G, Furthmüller J. Efficiency of ab-initio total energy calculations for metals and semiconductors using a plane-wave basis set. Comput Mater Sci, 1996, 6: 15-50

47 Perdew JP, Yue W. Accurate and simple density functional for the electronic exchange energy: Generalized gradient approximation. Phys Rev B, 1986, 33: 8800-8802

48 Perdew JP, Burke K, Ernzerhof M. Generalized gradient approximation made simple. Phys Rev Lett, 1996, 77: 3865-3868

49 Grimme S, Antony J, Ehrlich S, et al. A consistent and accurate $a b$ initio parametrization of density functional dispersion correction (DFT-D) for the 94 elements H-Pu. J Chem Phys, 2010, 132: 154104

50 Yang Y, Gao F, Gao S, et al. Origin of the stability of twodimensional perovskites: a first-principles study. J Mater Chem A, 2018, 6: 14949-14955

51 Wei S, Zunger A. Band offsets and optical bowings of chalcopyrites and Zn-based II-VI alloys. J Appl Phys, 1995, 78: 3846-3856

52 Butler KT, Frost JM, Walsh A. Band alignment of the hybrid halide perovskites $\mathrm{CH}_{3} \mathrm{NH}_{3} \mathrm{PbCl}_{3}, \mathrm{CH}_{3} \mathrm{NH}_{3} \mathrm{PbBr}_{3}$ and $\mathrm{CH}_{3} \mathrm{NH}_{3} \mathrm{PbI}_{3}$. Mater Horiz, 2015, 2: 228-231

53 Lindblad R, Bi D, Park BW, et al. Electronic structure of $\mathrm{TiO}_{2} /$ $\mathrm{CH}_{3} \mathrm{NH}_{3} \mathrm{PbI}_{3}$ perovskite solar cell interfaces. J Phys Chem Lett, 2014, 5: 648-653

54 Mosconi E, Ronca E, De Angelis F. First-principles investigation of the $\mathrm{TiO}_{2}$ /organohalide perovskites interface: The role of interfacial chlorine. J Phys Chem Lett, 2014, 5: 2619-2625

55 Li W, Niu S, Zhao B, et al. Band gap evolution in RuddlesdenPopper phases. Phys Rev Mater, 2019, 3: 101601

56 Shang Q, Li C, Zhang S, et al. Enhanced optical absorption and slowed light of reduced-dimensional $\mathrm{Cs} \mathrm{PbBr}_{3}$ nanowire crystal by exciton-polariton. Nano Lett, 2020, 20: 1023-1032

Acknowledgements This work was financially supported by the National Natural Science Foundation of China (11804058, 61571415, 11674310 and 61622406). Cheng $\mathrm{Y}$ thanks the financial support from RIE2020 AME Programmatic Grant A18A1b0045 funded by A*STARSERC, Singapore. Cheng Y and Zhang G are grateful for the supports from the Agency for Science, Technology and Research (A*STAR) and the use of $A^{\star}$ STAR Computational Resource Centre, Singapore (ACRC) and National Supercomputing Centre, Singapore (NSCC).

Author contributions Huang L conceived and conducted the calculations, analyzed the results and wrote the paper; Cheng Y and Li J supervised the project, analyzed the results and revised the paper. Dong $\mathrm{H}$ and Huo $\mathrm{N}$ performed some calculations and analyzed the results. Zheng $\mathrm{Z}$ analyzed the results of band alignment. Deng $\mathrm{H}$ and Zhang G analyzed the results and revised the paper. All authors contributed to the general discussion.

Conflict of interest The authors declare that they have no conflict of interest. 


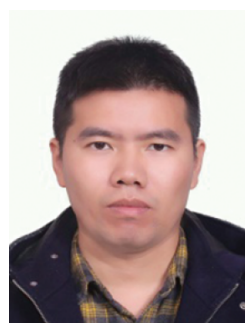

Le Huang received his Bachelor degree from Lanzhou University, China in July 2012, and $\mathrm{PhD}$ degree from the Institute of Semiconductors, Chinese Academy of Sciences in January 2017. He joined Guangdong University of Technology in 2017 and has been working there till present. His research interests include electronic and optical properties of perovskite materials and low-dimensional semiconductors.

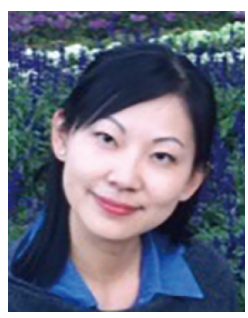

Yuan Cheng is currently a Senior Scientist in the Institute of High Performance Computing (IHPC) in Singapore. She received her Bachelor degree from Fudan University, China in July 2003, and PhD degree from National University of Singapore in April 2008. She joined IHPC in 2007. Dr. Yuan Cheng's research interest involves mechanical and physical properties of bioand nano-materials, and machine-learningassisted material design.

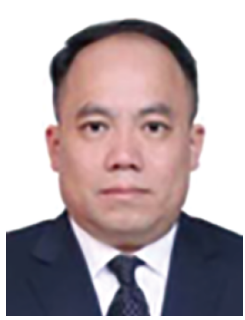

Jingbo Li received his $\mathrm{PhD}$ degree from the Institute of Semiconductors, Chinese Academy of Sciences, in 2001. Then, he spent six years at the Lawrence Berkeley National Laboratory and National Renewable Energy Laboratory in USA. From 2007 to 2019, he worked as a professor at the Institute of Semiconductors, Chinese Academy of Sciences. Since 2019, he has been a fulltime professor and the dean of the Institute of Semiconductors, South China Normal University. His research interests include the design, fabrication, and application of novel nanostructured semiconductors.
高效钲针矿太阳能电池中缓冲层界面工程的深入 理解: 第一性原理研究

黄乐 ${ }^{1}$, 董华锋 ${ }^{2}$, 霍能杰 ${ }^{3}$, 郑照强, 邓惠雄 ${ }^{4}$, 张刚 $^{5}$, 程渊 ${ }^{5^{*}}$, 李京波 ${ }^{1,3^{*}}$

摘要 近年来钘钛矿太阳能电池的能量转换效率迅速提高. 界面工 程是进一步改善钙钛矿太阳能电池性能的有前途的途径. 本文中, 我们进行第一性原理计算, 以探索四种候选缓冲材料 (MACl, MAI, $\mathrm{PbCl}_{2}$ 与 $\mathrm{PbI}_{2}$ ) 对 $\mathrm{MAPbI}_{3}$ 吸收层与 $\mathrm{TiO}_{2}$ 之间界面电子结构的影响. 我 们发现MAX $(\mathrm{X}=\mathrm{Cl}, \mathrm{I})$ 作为缓冲层将引入高电子势垒并增强电子空穴复合. 此外, MAX不能很好地钝化表面状态. $\mathrm{PbI}_{2}$ 的导带最小 值远低于 $\mathrm{MAPbI}_{3}$ 吸收层的导带最小值, 这极大地限制了吸收层的 能带弯曲和太阳能电池的开路电压. 另一方面, 合适的带边能级位 置, 与 $\mathrm{TiO}_{2}$ 表面的小的晶格失配以及出色的表面钝化性能使得 $\mathrm{PbCl}_{2}$ 成为钻钛矿太阳能电池吸收层/电子传输层界面工程的有希 望的缓冲材料. 因此, 我们在这项工作中获得的结果可以使人们对 具有缓冲层的界面工程的效果有更深入的理解，这有利于改善钻 钛矿太阳能电池和相关光电器件的性能. 